Provided for non-commercial research and education use. Not for reproduction, distribution or commercial use.

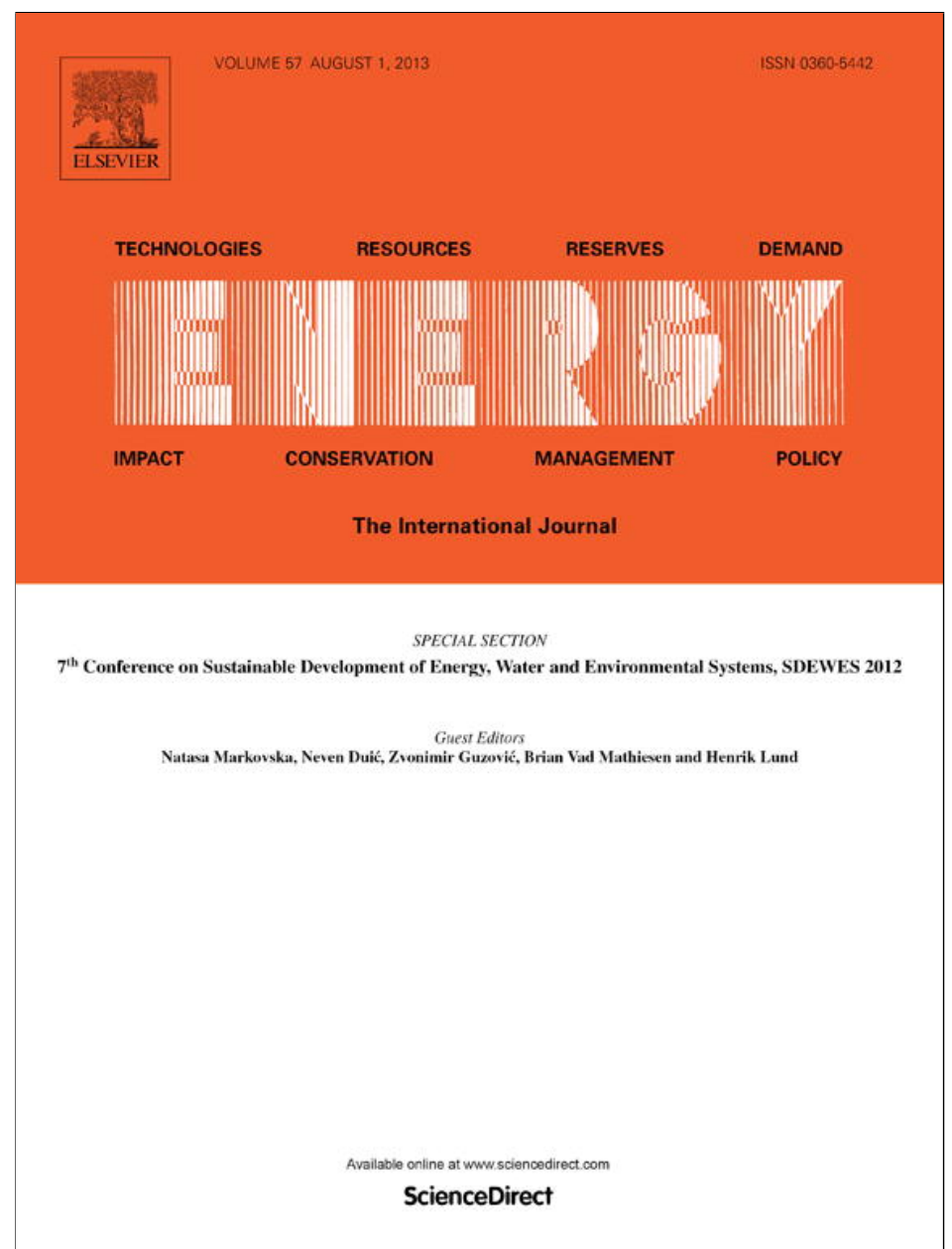

This article appeared in a journal published by Elsevier. The attached copy is furnished to the author for internal non-commercial research and education use, including for instruction at the authors institution and sharing with colleagues.

Other uses, including reproduction and distribution, or selling or licensing copies, or posting to personal, institutional or third party websites are prohibited.

In most cases authors are permitted to post their version of the article (e.g. in Word or Tex form) to their personal website or institutional repository. Authors requiring further information regarding Elsevier's archiving and manuscript policies are encouraged to visit:

http://www.elsevier.com/authorsrights 


\title{
The looming revolution: How photovoltaics will change electricity markets in Europe fundamentally
}

\author{
Reinhard Haas ${ }^{\mathrm{a}, *}$, Georg Lettner ${ }^{\mathrm{a}}$, Hans Auer ${ }^{\mathrm{a}}$, Neven Duic ${ }^{\mathrm{b}}$ \\ ${ }^{a}$ Energy Economics Group, Vienna University of Technology, A-1040 Vienna, Austria \\ ${ }^{\mathrm{b}}$ University of Zagreb, Croatia
}

\section{A R T I C L E I N F O}

\section{Article history:}

Received 7 October 2012

Received in revised form

13 March 2013

Accepted 16 April 2013

Available online 3 June 2013

\section{Keywords:}

Photovoltaics

Electricity markets

Wholesale electricity prices

Grid parity

\begin{abstract}
A B S T R A C T
The increase in PV (photovoltaic) capacities in Germany had since 2011 on some days already significant impacts on spot market prices at the German electricity exchange. The core objective of this paper is to investigate the possible effects of a further uptake of PV on the prices in electricity markets. We analyze two major effects: (i) the direct impact of PV at specific times of the year when PV shifts the supply curve of conventional electricity virtually out of the market, leading to temporarily very low market prices close to Zero; (ii) the indirect impact of PV (and wind) on the costs at which fossil capacities are offered at times when renewable energy sources are scarce. The major effects of these developments on the electricity markets will be: (i) a much higher price volatility from hour-to-hour and day-to-day; (ii) higher prices for electricity from fossil capacities and storage technologies for balancing the intermittent renewable generation; and (iii) growth of balancing markets and intensified competition at the level of decentralized balancing organizations.
\end{abstract}

(c) 2013 Elsevier Ltd. All rights reserved.

\section{Introduction}

For a long time PV (photovoltaic) systems have been seen as a mature and environmentally benign technology with a huge potential [1] for electricity generation yet at very high costs [2-6]. In recent years a remarkable increase in capacities took place in various countries, yet among all countries with significant PV installations Germany showed the most continuous evolution. The major reason was the drop of costs of PV systems with Germany leading, see Fig. 1. By the end of 2012 Germany exceeded the $30 \mathrm{GW}$ threshold, Fig. 1, and also in the next years at least a continuous further growth of PV capacities in Germany is expected. The minimum up to 2020 from a set of different scenarios (Quaschnig, [7]) is $50 \mathrm{GW}$. This is about half of total fossil and nuclear capacity in Germany in 2011. Moreover, the looming grid-parity - costs of PV lower than the household electricity price - will further emphasize this trend because PV will become economically more attractive.

The core objective of this paper is to investigate the possible effects of such a further uptake of PV on the prices in an electricity market. Because Germany is currently already influenced by this effect we explain the likely consequences for the example of this market. ${ }^{1}$ We analyze two major effects: (i) the direct impact of PV at

\footnotetext{
* Corresponding author. Fax: +43158801 370397.

E-mail address: haas@eeg.tuwien.ac.at (R. Haas).

1 Despite this analysis is conducted for a rather small area the perceptions and conclusions of this analysis can be used in many countries world-wide.
}

specific times of the year when PV shifts the supply curve of conventional electricity virtually out of the market leading to temporarily very low market prices close to Zero; (ii) the indirect impact of PV (and wind) on the costs at which fossil and natural gas capacities are offered at times when RES (renewable energy sources) are scarce.

\section{How prices in electricity markets come about}

To investigate how PV will influence the prices in electricity markets it is first important to explain the current market structure and the market rules. Most important is to understand how prices in European electricity markets currently come about. The price formation is currently mainly based on a fundamental approach where the intersection of a merit order supply curve and demand at every point-of-time gives the corresponding market price.

Such a typical merit order supply curve for a specific point-oftime with conventional capacities is depicted in Fig. 2. This typical historical pattern of electricity generation in the Western European electricity market consisted since decades of conventional fossil, nuclear and large hydro capacities. As shown in Fig. 3, the intersection of the supply curve with demand determines the market clearing price at the short-term marginal costs of the system.

This fundamental approach of price formation has led to quite different price developments in different European electricity submarkets from 2000 to 2012, see Fig. 4. In this period a high volatility and considerable differences of electricity spot market prices 


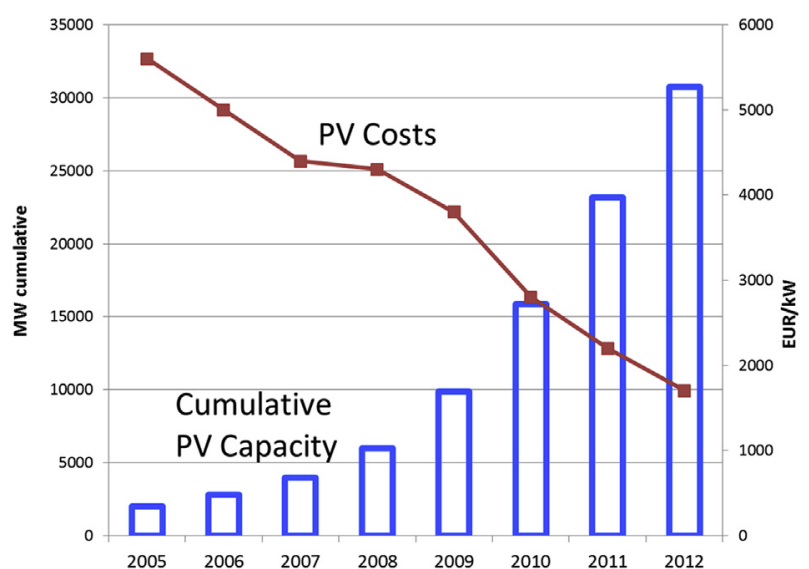

Fig. 1. Development of cumulated PV capacities and system prices in Germany in recent years. (Sources: [10-12], http://www.renewablesinternational.net/2012-recordyear-for-pv-in-germany/150/510/60257/, Figures 2012 preliminary).

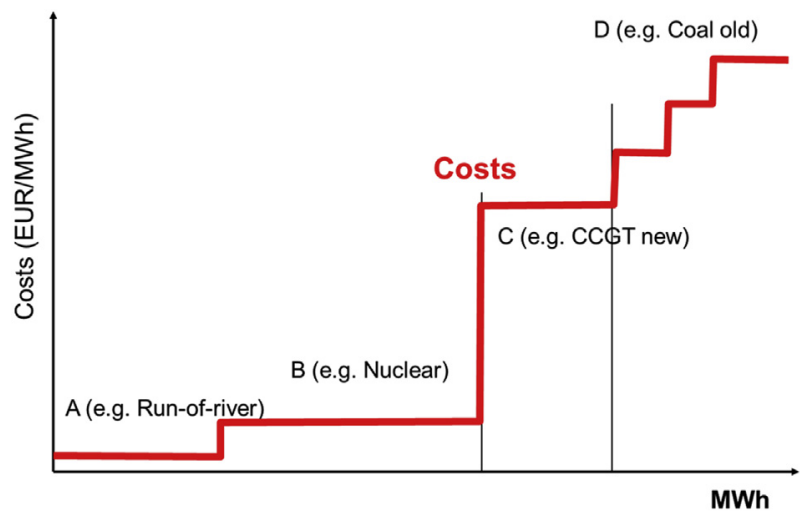

Fig. 2. Typical conventional merit order supply curve based on short-term marginal costs for a specific point-of-time with conventional capacities (incl. large run-of-river hydro). (Source: own illustration).

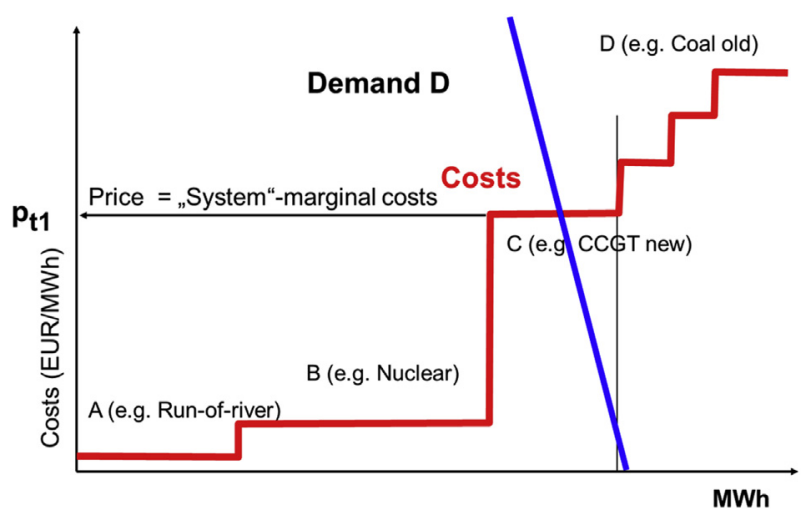

Fig. 3. How prices come about in markets with conventional capacities (incl. large hydro): intersection of supply curve with demand gives electricity price at the short term system marginal costs. (Source: own illustration).

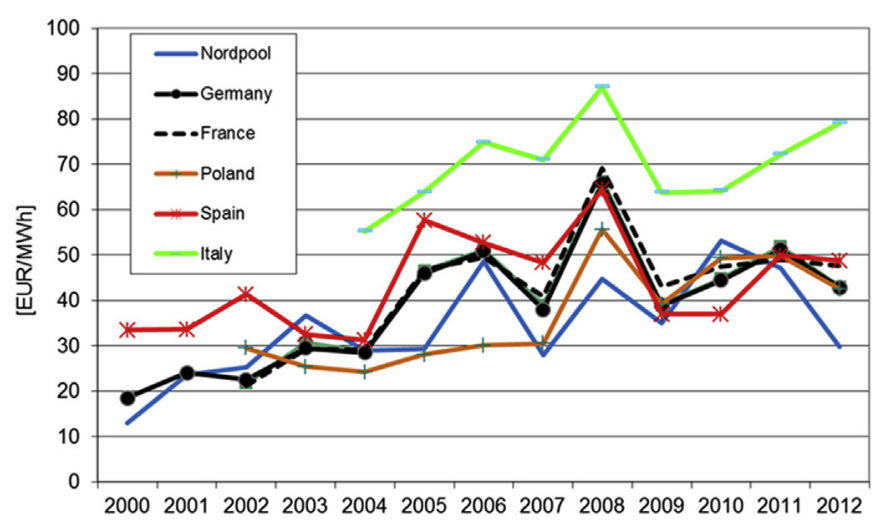

Fig. 4. Price developments in different European electricity markets 2000-2012. (Source: Homepages of different energy exchanges, Figures for 2012 preliminary).

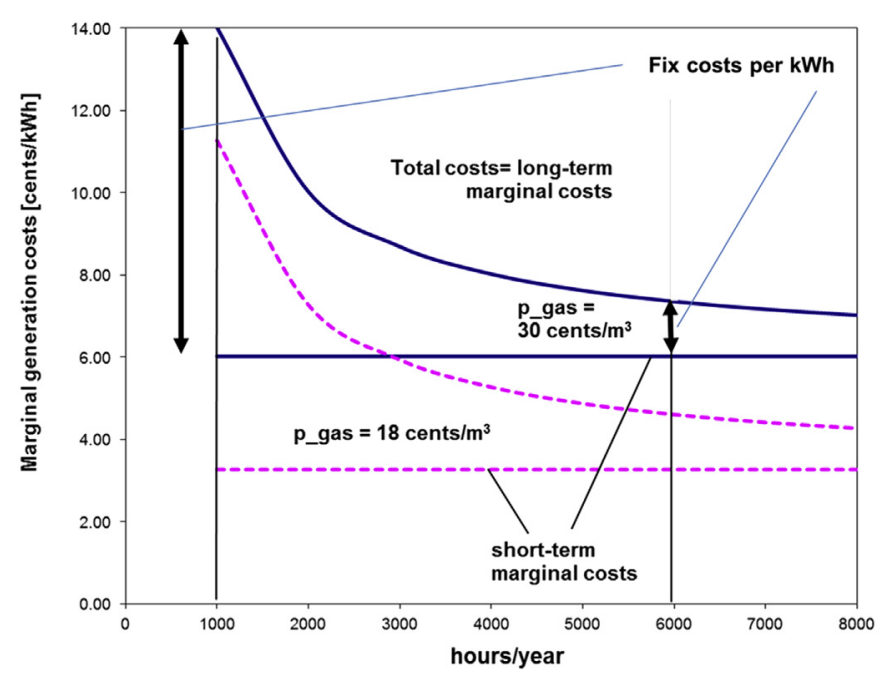

Fig. 5. Total and variable (short term) electricity generation costs of a CCGT depending on yearly full load hours. (Source: own illustration).

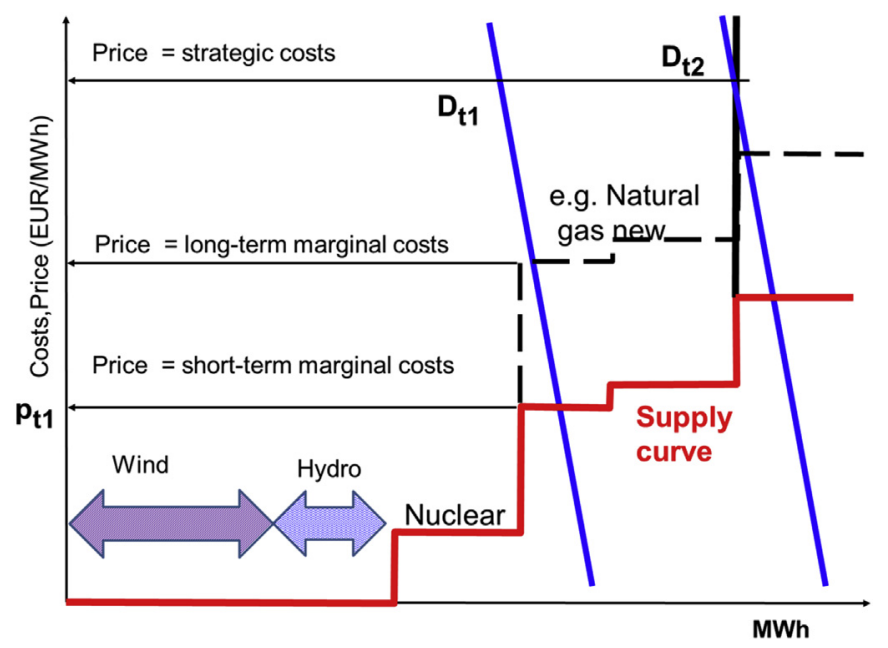

Fig. 6. Merit order supply curve with additional wind capacities (incl. run-of-river hydro) at off-peak time with total costs or strategic bidding for conventional capacities. (Source: own illustration). 


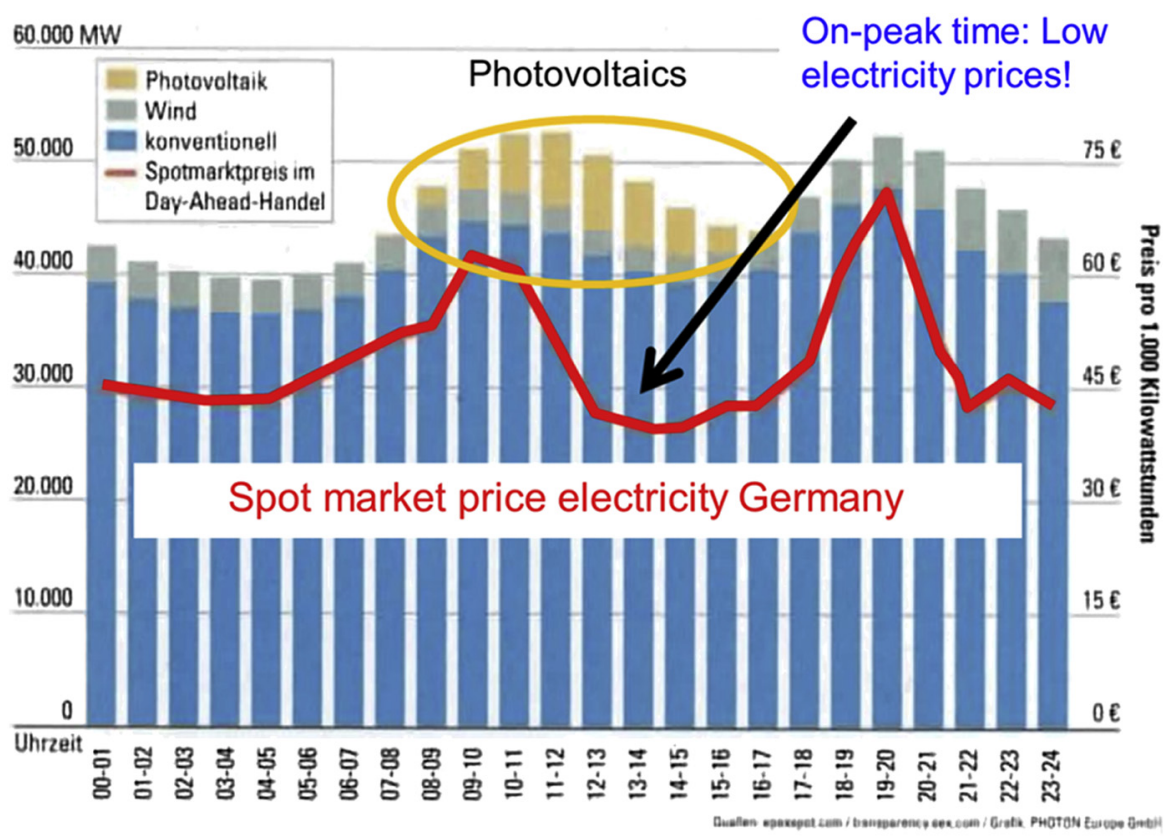

Fig. 7. Example for the impact of PV capacities on the price developments in the German electricity market on 22nd October 2011.

between different sub-markets are observed. Italy tends to experience higher prices and more volatility due to its over-reliance on imported electricity and congested cross-border transmission lines. In the case of the NORDPOOL, which includes Sweden, Norway, Finland, and portions of Denmark, the pattern is different due to heavy reliance on hydro and lack of strong interconnection with Continental Europe. Yet, the other countries illustrated in Fig. 4 show a remarkable convergence of prices even in the case of the isolated market of Spain, which is not yet fully integrated into the European network due to transmission limitations. Regarding the magnitude of prices the reason for high prices in 2008 in Continental Europe was the low hydro availability while the falling prices after 2008 may at least to some extent be attributed to the economic crisis.

\section{The indirect impact of temporarily higher shares of renewables on the pricing of fossil capacities in electricity markets}

In a market with large shares of renewable energy sources the role of conventional capacities will change see e.g. Auer [16], Pantos [18], Hasoni/Hosseini [19], Carraretto [25]. In Figs. 2 and 3 the supply curve is still based on the short-term marginal costs of the fossil capacities. Usually for natural gas this corresponds to about 6000 full-load hours per year. But what will happen, if the full-load hours per year drop to $1000-2000 \mathrm{~h} /$ year?

Fig. 5 depicts the total and the variable (short term) electricity generation costs of a new combined-cycled gas turbines (CCGT) depending on yearly full-load hours. As can be seen the share of fix costs is considerably higher when full-load hours are low (e.g. $1000 \mathrm{~h} /$ $\mathrm{yr})^{2}$ than when full-load hours are high (e.g. 6000 h/yr). Historically, different types of fossil plants were dispatched to meet the load over the course of all hours in a year and it was generally possible to recover the fixed costs when more expensive plants, usually gas-fired peaking units, set the price. In recent years, frequently old and mostly depreciated coal plants determined the short-term marginal costs,

\footnotetext{
${ }^{2}$ Of course, these full-load hours will also vary year-by-year. They will be lower in years with higher hydro power than on average and vice versa.
}

allowing new peaking units such as CCGTs to recover their fixed costs. In a future where renewables with virtually zero marginal costs set market clearing prices this may no longer be the case.

This leads to the perception that regardless of what such schemes may be called, pricing with long term marginal costs (incl. the capacity costs, the so-called levelized costs of electricity) or even shortterm strategic costs becomes much more important than today.

How the growth of renewables might impact future pricing strategies of fossil or biomass power plants over time is a subject of speculation. As schematically shown in Fig. 7, the merit order supply curve and the high and low demand curves are affected based on the availability of renewables, which tend to be intermittent and not entirely predictable. The illustration shows three examples for supply curves: merit order supply curves for short-term vs. longterm marginal costs of CCGT plants (see also Walls [17].) and a supply curve for strategic bidding, which is shown as a vertical line.

Depending on where the supply and demand curves intersect, different prices would prevail. The price may be extremely high in the case of strategic bidding - not sustainable in the long run - or lower when long-term marginal costs are included, or even lower if short-term marginal costs prevail.

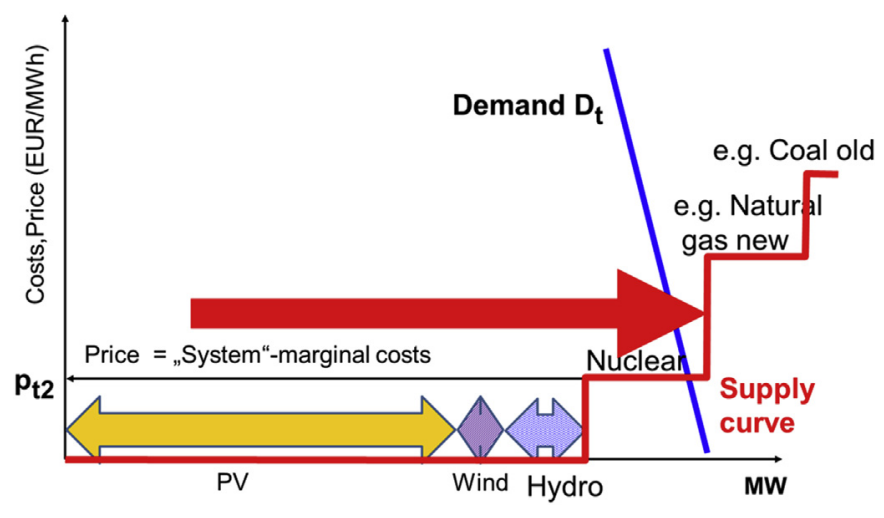

Fig. 8. Merit order supply curve with additional wind and PV capacities (incl. run-ofriver hydro) at on-peak time of a nice summer day with short term marginal costs for conventional capacities. 


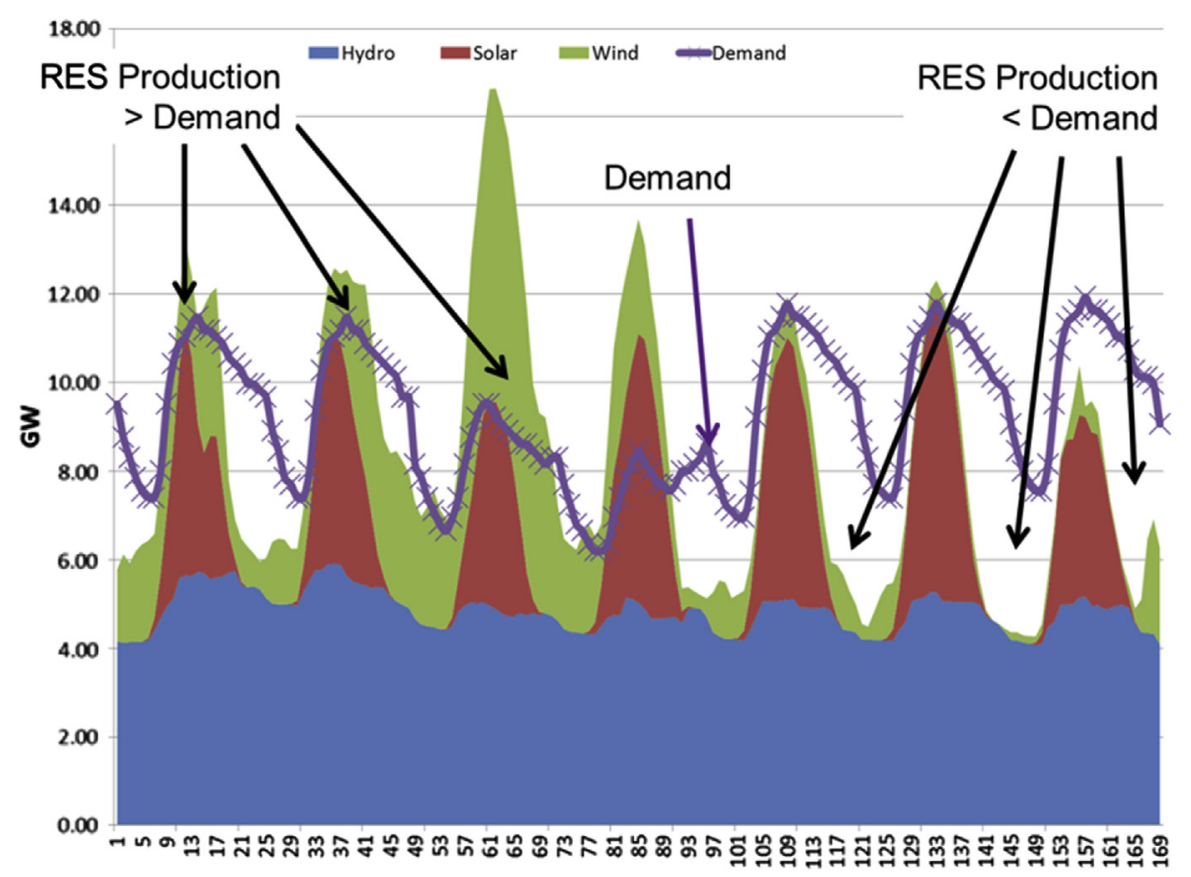

Fig. 9. Development of wind and PV electricity (incl. large hydro) over a week on an hourly base in comparison to demand. (Source: own illustration).

\section{The specific impact of PV on the electricity market price}

That RES have an impact on electricity prices (or in former regulated markets at least at the conceived marginal costs of electricity generation) are already known since volatile hydro power was used for electricity generation. Later, in the time of starting wind booms (about 2007-2009, in Denmark already earlier), there was experience with temporarily high wind in the systems and sometimes even negative prices (see also [9,23,24,26-28]). However, these effects due to wind happened mostly at off-peak times (sometimes also due to wrong or careless wind forecasts).

What makes PV now specifically different? Fig. 7 illustrates an example from Germany for the impact of PV capacities on the price developments in the German electricity market on 22nd October 2011. As this Figure depicts on sunny days PV electricity generation follows the daily load profile and on these days it substitutes virtually completely the former production of hydro storages. We can see that around noon - when prices historically were typically high - prices dropped. In addition, PV electricity changes the increase of prices at noon to a decrease.

The explanation is simple. Fig. 8 shows the merit order supply curve with additional wind and PV capacities (incl. large hydro) at on-peak time of a nice summer day with short term marginal costs for conventional capacities. On such a sunny day with ample solar generation, the supply curve is shifted to the right as schematically shown in Fig. 8, which essentially pushes nuclear and fossil fueled generation "out of the market." If the impact of PVs on a sunny day in October, not a peak period for solar generation in Germany, can be as dramatic as is shown on Fig. 7, one can expect much more dramatic impacts on market prices during future summer months.

The development of wind and PV electricity (incl. run-of-river hydro) over a week in summer (based on synthetic data over an average year in Austria/Germany) on an hourly base in comparison to demand is depicted in Fig. 9. It can clearly be seen that there are times with large amounts of excess capacity from RES and times with tremendous capacity lack.

The consequences of large amounts of electricity from RES on electricity prices in a dynamic picture for this example of a week in summer (based on synthetic data over an average year in Germany) are depicted in Fig. 10. The graph shows significant volatilities in electricity market prices with total costs charged for conventional capacities black solid line - ranging from zero to 14 cents $/ \mathrm{kWh}^{3}$ within very short-term time intervals. In practice, of course, the prices may not go exactly to zero but would be rather low or even negative.

Another perception of Fig. 10 is that the price spread increases. But in future high prices will not necessarily appear at peakdemand times but at times with low availability of electricity from RES and the low price level will be associated with high production from RES. This will also change the operation of pumped hydro facilities and lead to new investment in energy storage technologies to take advantage of significant price differentials. Over time, the familiar patterns of the night-to-day-shift of generation will change in response to the unpredictable and variable rhythm of renewable generation. The most likely consequence of increased price volatility will be that storages and flexible peaking units become much more valuable than they currently are.

The following remark is also important. For the price spread effect it does not make a difference whether PV electricity is fed into the grid or directly used by the customer. As the total demand profile over a day will not change (except some possible minor shifts due to individual customer behavior) the price effects described in Fig. 10 will be in principle the same.

\section{Future prospects for PV: looming grid parity?}

All in all these European developments led to a significant cost decrease which bring PV systems on the verge to costcompetitiveness with household electricity prices, the so-called "grid parity" in most cases before 2020 (see Lopez and Haas [6], Breyer and Gerlach [13], Lund [22]). Possible developments for Germany up to 2020 for small-scale systems ( $<30 \mathrm{~kW}$ ) in an upper and a lower "corridor" depending on the overall capacity of systems

\footnotetext{
${ }^{3}$ The 14 cents/kWh in this example results from Fig. 5 with full load hours of about $1000 \mathrm{~h} / \mathrm{yr}$.
} 


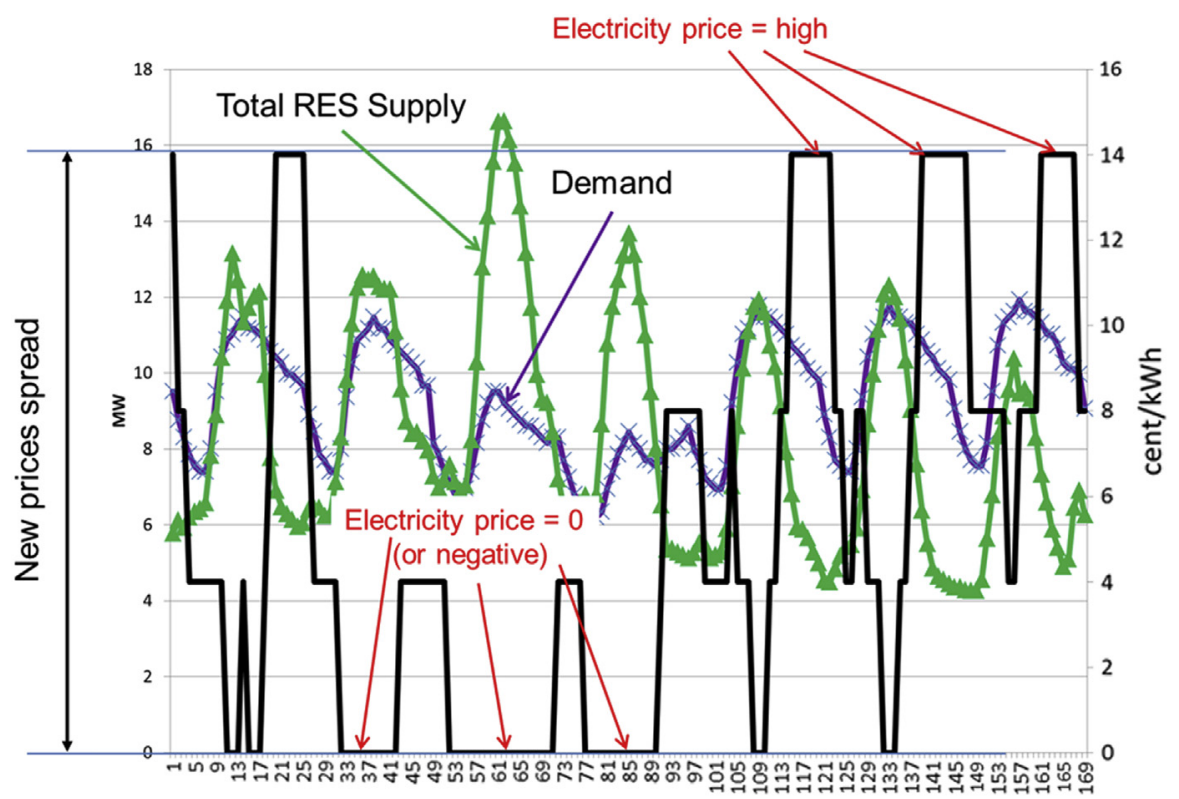

Fig. 10. Development of total RES supply (wind, PV and hydro run-of-river) over a week on an hourly base in comparison to demand and the resulting electricity market prices with total costs for conventional capacities. (Source: own illustration).

installed are depicted in Fig. 11. In this Figure also household electricity prices are included. For small-scale systems in the lower corridor scenario the so-called grid parity could already be brought about before 2015. The major latest development which are important in this Figure are the FIT of 29 cent/kWh for 2011 in Germany and of 24 cent/kWh for 2012 (see Breyer and Gerlach [13]).

In total the situation for Germany can be considered rather promising for PV grid parity. The only reason why there might be some backlash would be if the market - which is still very sensitive - depending on imports from China and the effective financial support from government - collapses and system prices start to increase again as depicted in Haas [8] for the past. Yet, it is also important to state that grid parity does by far not mean fully economic competitiveness. This depends strongly on the feed-in price for the remaining electricity. However, if a net metering approach is introduced this criteria is fulfilled.

\section{Future challenges}

The above described developments and effects lead to further reflections and requests that may accompany the further uptake of PV. The most important are (see also Auer [9], Nielsen et al. [17], Pantos [18], Wen [20], Lund [21], Lund [22]):

- From a rigid supply system to a breathing system: We think that the major change must be a paradigm change in our understanding of the whole electricity system - from generation over "smart" grids to electricity-based services finally provided. This major change in thinking is to switch from an unflexible rigid static one-way system to an over-all "breathing" system, which allows bi-directional flows, technical flexibility in the system, incl. demand-side manangement, load management from utilities and storages (see e.g. Krajacic et al. [15]) which also contribute to "breathing".

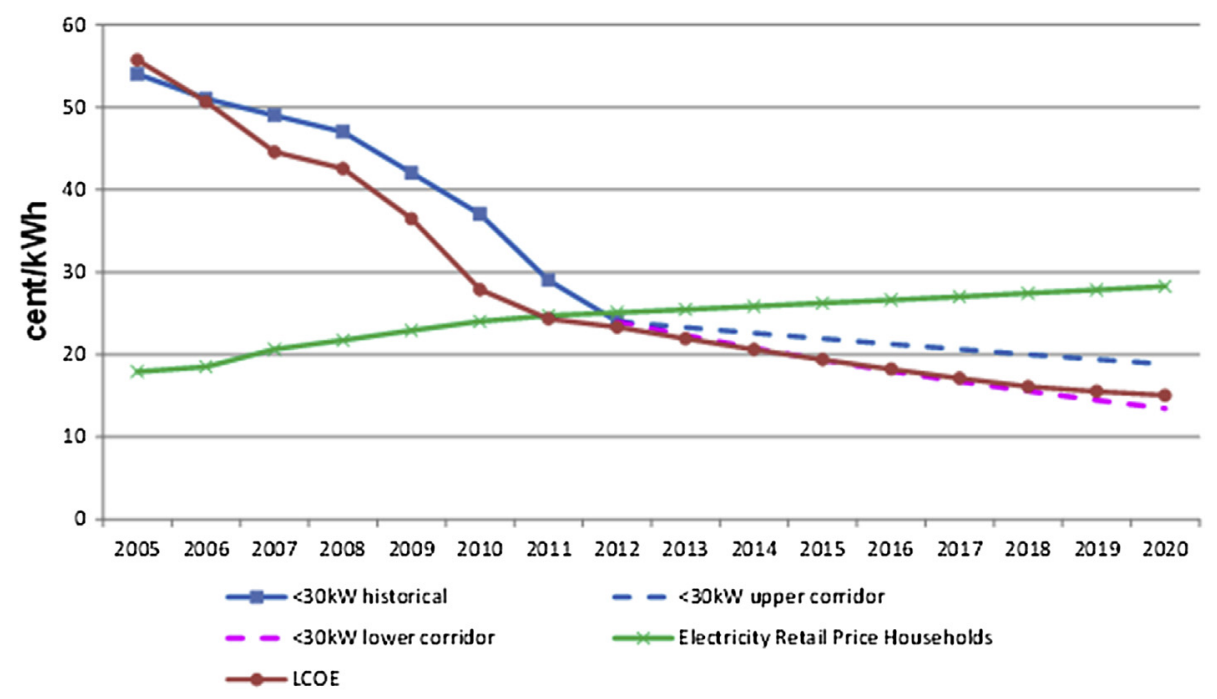

Fig. 11. Historical development of PV FIT for small systems in Germany and expectations up to 2020 vs. household electricity prices leading to "grid parity" between 2013 and 2015. (Sources: $[13,14,29])$. 
- Are there needs for capacity markets? The discussion of the economics of remaining fossil power plants - see Figs. 5 and 6 - leads to the question whether there is a need for so-called capacity markets. The major argument of the proponents of this idea is that only if a fixed "stand-by fee" is paid for these mainly fossil plants, operators/owners of these plants will be retained from closing down these plants respectively temporarily high strategic prices will be avoided.However, in practice it is only necessary to get rid of the simplified and anachronistic argument of the initial theoretical requests of liberalized markets that prices must equal short-term marginal costs.

- New market structures: With respect to time-dependent market structures different new patterns will emerge. Regarding the role of hedging and future contracts an argument raised recently is that in markets with high shares of renewable energy sources no hedging is possible and future markets will break down. We think that actually the opposite will be true: With hedging and tradable long-term contracts these instruments will take over to a large extent the role of capacity markets. E.g., long-term contracts traded years ahead on an annual basis will serve to reserve (and ensure) long-term capacity. The closer the delivery date comes the more fine-tuned will be the capacity reservation due to purchasing long-term contracts. E.g. if good hydro power conditions are observed less capacity will be hedged than vice versa. On the other hand there is a growing relevance of shortterm markets like intraday- and secondary energy markets. In this context it is likely from our perspective that also "longer" term markets for secondary energy will emerge.

\section{Conclusions}

The major conclusion of this analysis is that the electricity supply system and the electricity market of the future will look quite different than today while many of the fundamentals will remain. In addition to the effects of renewables which are already known, a new aspect will be that the variability of their generation will further increase if much higher quantities of wind and PV are fed into the grid, is looming today for Germany and other European countries. The effects of these developments on the prices in electricity markets will be:

i. Much higher price volatility from hour-to-hour and day-to-day;

ii Higher prices for electricity from fossil capacities and storage technologies for balancing the intermittent renewable generation; and

iii Growth of balancing markets and intensified competition at the level of decentralized balancing organizations.

\section{References}

[1] Dinçer F. The analysis on photovoltaic electricity generation status, potential and policies of the leading countries in solar energy. Renewable and Sustainable Energy Reviews January 2011;15(1):713-20.
[2] Raugei M, Frankl Paolo. Life cycle impacts and costs of photovoltaic systems: current state of the art and future outlooks. Energy 2009;34:392-9.

[3] Haas R. The value of photovoltaic electricity for society. Solar Energy 1995;54(1):25-31.

[4] Haas R. Market deployment strategies for photovoltaics in the built environment: an international review. Renewable and Sustainable Energy Reviews 2003; 7:271-315.

[5] Dusonchet L, Telaretti E. Economic analysis of different supporting policies for the production of electrical energy by solar photovoltaics in western European union countries. Energy Policy 2010;38:3297-308.

[6] Lopez Polo A, Haas R. An international overview of promotion policies for grid connected PV systems. Progress in Photovoltaics 2011;20:2012.

[7] Quaschnig V. Wieso eigentlich nur 3,5 GW pro Jahr? Sonne, Wind und Wärme $8 / 2012$.

[8] Haas R. Progress in markets for grid-connected PV systems in the built environment. Progress in Photovoltaics 2004;12:427-40.

[9] Auer J. Grid regulation in competitive electricity markets. Habilitation thesis. EEG, Vienna University of Technology; 2011.

[10] EPIA. Market report 2011. Brussels 2012.

[11] Trends in photovoltaic applications, survey report of selected IEA countries between 1992 and 2010. IEA; 2012.

[12] PHOTON various issues 12/2012.

[13] Breyer Ch, Gerlach A. Global overview on grid-parity event dynamics. In: Proc. 25th PVSEC 2010.

[14] Energy prices \& taxes. IEA; 2011.

[15] Krajačić G, Duić Neven, Tsikalakis Antonis, Zoulias Manos, Caralis George, Panteri Eirini, et al. Feed-in tariffs for promotion of energy storage technologies. Energy Policy 2011;39:1410-25.

[16] Walls WD, Rusco Frank W, Ludwigson J. Power plant investment in restructured markets. Energy 2007;32:1403-13.

[17] Nielsen S, Sorknæs P, Østergaard PA. Electricity market auction settings in a future Danish electricity system with a high penetration of renewable energy sources - a comparison of marginal pricing and pay-as-bid. Energy 2011;36: 4434-44.

[18] Pantoš M. Market-based congestion management in electric power systems with increased share of natural gas dependent power plants. Energy 2011;36(7):4244-55.

[19] Hasani M, Hosseini Seyed Hamid. Dynamic assessment of capacity investment in electricity market considering complementary capacity mechanisms. Energy 2011;36:277-93.

[20] Wen L, Lund H, Mathiesen BV. Large-scale integration of wind power into the existing Chinese energy system. Energy 2011;6:4753-60.

[21] Lund PD. Boosting new renewable technologies towards grid parity - economic and policy aspects. Original Research Article. Renewable Energy 2011;36:2776-84.

[22] Lund H, Andersen Anders N, Østergaard Poul Alberg, Mathiesen Brian Vad, Connolly David. From electricity smart grids to smart energy systems - a market operation based approach and understanding. Energy 2012;42:96102.

[23] Lund H. Large-scale integration of wind power into different energy systems. Energy 2005;30:2402-12.

[24] Moreno B, López Ana J, García-Álvarez María Teresa. The electricity prices in the European Union. The role of renewable energies and regulatory electric market reforms, Energy. Energy 2012;48(1):307-13. Available online $20 / 7 / 2012$.

[25] Cristian Carraretto, Zigante Andrea. Interaction among competitive producers in the electricity market: an iterative market model for the strategic management of thermal power plants. Energy 2006;31:3145-58.

[26] Zubi Ghassan. Technology mix alternatives with high shares of wind power and photovoltaics-case study for Spain. Energy Policy 2011;39:8070-7.

[27] Hammons TJ. Integrating renewable energy sources into European grids. International Journal of Electrical Power \& Energy Systems 2008;30: 462-75.

[28] Nicolosi M. Wind power integration and power system flexibility-an empirical analysis of extreme events in Germany under the new negative price regime. Energy Policy 2010;38:7257-68.

[29] Wirth H. Aktuelle Fakten zur Photovoltaik in Deutschland. Fraunhofer ISE; 2012 